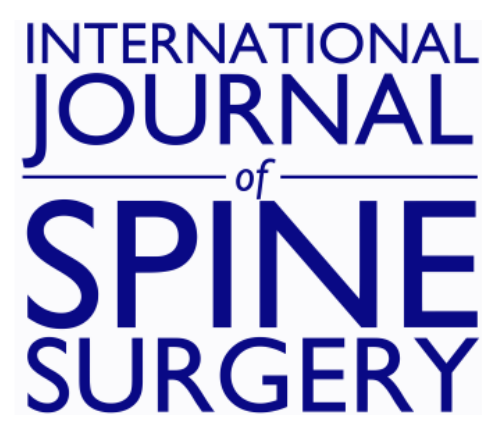

\title{
Endoscopic Transforaminal Lumbar Interbody Fusion With a Single Oblique PEEK Cage and Posterior Supplemental
} Fixation

\author{
Álvaro Dowling and Kai-Uwe Lewandrowski \\ Int J Spine Surg 2020, 14 (s3) S45-S55 \\ doi: https://doi.org/10.14444/7126 \\ http://ijssurgery.com/content/14/s3/S45 \\ This information is current as of April 25, 2023.
}

Email Alerts Receive free email-alerts when new articles cite this article. Sign up at: http://ijssurgery.com/alerts 


\title{
Endoscopic Transforaminal Lumbar Interbody Fusion With a Single Oblique PEEK Cage and Posterior Supplemental Fixation
}

\author{
ÁlVARO DOWLING, MD, ${ }^{1} \mathrm{KAI}-\mathrm{UWE}$ LEWANDROWSKI, $\mathrm{MD}^{2}$ \\ ${ }^{I}$ Endoscopic Spine Clinic, Santiago, Chile, Department of Orthopaedic Surgery, USP, Ribeirão Preto, Brazil, ${ }^{2}$ Center for Advanced Spine Care of Southern \\ Arizona and Surgical Institute of Tucson, Tucson, Arizona, Department Neurosurgery, UNIRIO, Rio de Janeiro, Brazil, Department of Orthopaedics, Fundación \\ Universitaria Sanitas, Bogotá, DC, Colombia
}

\begin{abstract}
Background: To demonstrate the feasibility of an endoscopically assisted minimally invasive surgery transforaminal lumbar interbody fusion (MIS-TLIF) and to study clinical outcomes with the use of a static oblique bulletshaped cannulated poly-ether-ether-ketone (PEEK) lumbar interbody fusion cage in conjunction with platelet enriched plasma infused allograft cancellous chips and posterior supplemental fixation.

Methods: In this retrospective study of 43 patients who underwent endoscopically assisted MIS-TLIF for spondylolisthesis $(53.5 \%)$ and stenosis $(46.3 \%)$, the Oswestry Disability Index, the visual analog scale (VAS) for back and leg pain, and the modified Macnab criteria were used as primary clinical outcome measures. Clinical outcomes were cross-tabulated against fusion grade using the Bridwell classification of interbody fusion.

Results: The majority of patients $(90.7 \%)$ had excellent $(8 / 43 ; 18.6 \%)$ and good $(31 / 43 ; 72.1 \%)$ Macnab outcomes. There were significant VAS back score reductions from an average preoperative values of 8.9070 to a postoperative VAS score of 3.8605 , and a score of 2.7674 at final follow-up $(P<.0001)$. The reductions in the VAS leg scores were also significant from preoperative score of 5.58 to a postoperative value of 2.16 , and a final follow-up score of $1.67(P<.0001)$; the Oswestry Disability Index score went from a preoperative value of 54.4 to 23.3 postoperatively and 18.5 at the final follow-up $(P<.0001)$. The vast majority of patients $(92.9 \%)$ with Bridwell grade I fusion had excellent and good Macnab outcomes $(P=.027)$.

Conclusions: The authors recommend the use of an endoscope as an adjunct to MIS-TLIF, a minimally invasive spinal surgery technique in which many surgeons may be well versed and have a great deal of experience. Clinical outcomes with the endoscopic interbody fusion procedure with a static PEEK cage in conjunction with platelet-enriched bone allograft were favorable.

Level of Evidence: 3.

Clinical Relevance: Feasibility study.
\end{abstract}

Special Issue

Keywords: lumbar interbody fusion, minimally invasive, endoscopic, direct visualization

\section{INTRODUCTION}

In recent years, minimally invasive surgery (MIS) solutions have become more practical and suitable for routine clinical applications in spinal surgery. Initially, there was a learning curve to overcome, and many early studies demonstrated equivalent outcomes with slightly higher complication rates in some areas when compared to conventional open spine surgery. ${ }^{1,2}$ Subsequently, technology improvements were incorporated into many forms of postgraduate training programs, and the acceptance of MIS techniques into the mainstream of spine surgery is reflected in the plethora of published studies and presented podium papers at national and international spine meetings. ${ }^{3-6}$ Nowadays, the medium- to long-term clinical outcome difference for both traditional open and MIS spine surgery is widely considered minimal with MIS having some perioperative advantages, such as decreased blood loss, lower infection and complication rates, and shorter time to narcotic independence and return to work. $^{7-14}$ The contemporary MIS transforaminal lumbar interbody fusion (MIS-TLIF) has no significant disadvantages when compared with open TLIF or other standard lumbar fusion techniques. ${ }^{2,14}$ 


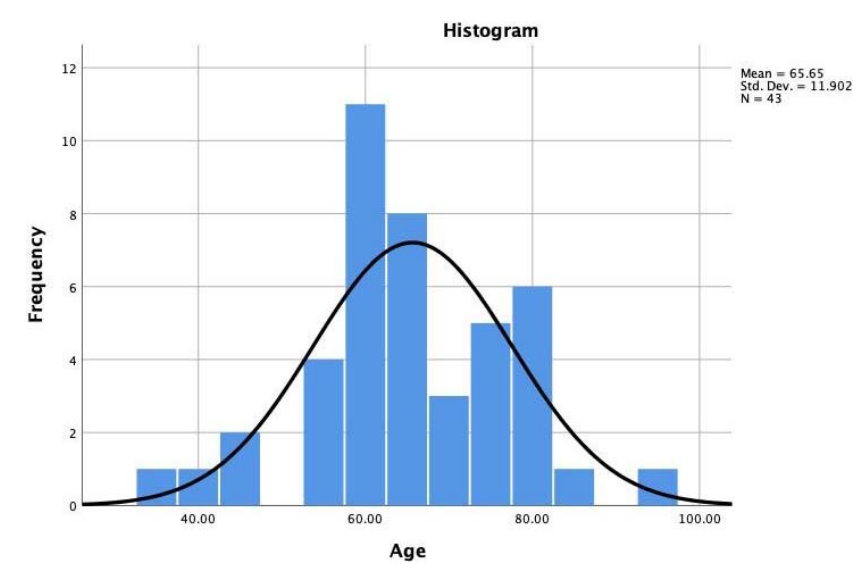

Figure 1. Age distribution of the 43 study patients with the superimposed expected normal distribution (black line). Patients' ages ranged from 35 to 93 years of age and averaged 65.66 years.

The combination of MIS with the endoscopic transforaminal approach allows us to minimize further the collateral damage from the surgical access, and has the unique advantage of direct visualization of critical anatomical structures and the release of nerve roots from compression or adhesions. ${ }^{15}$ It is also possible to create enough space for cage placement in the intervertebral space by performing a sizable foraminoplasty multiple in diameter than a typical 4.0-mm endoscopic power drill, with the latter being especially relevant at the L5-S1 level. The endoscopic transforaminal approach also achieves an excellent view of the vertebral endplate, while being able to control the quality of its preparation with the intent of minimizing breaking through into the subchondral bone, which is believed to be associated with cage subsidence and inferior clinical outcomes. ${ }^{12,16,17}$

In this case series, the authors present their outcome data with their approach to endoscopically assisted MIS-TLIF, where a single static cannulated poly-ether-ether-ketone (PEEK) cage was placed obliquely across the intervertebral disc space from a unilateral endoscopic approach. While this has been trialed, ${ }^{15,18,19}$ the authors' surgical protocol presented herein relies on the 3 pillars of successful clinical outcomes with spinal fusion: (1) wide decompression, (2) treatment of instability with instrumentation, and (3) vigorous bony fusion promoted via the abundance of biologically active bone graft, which in the case of the authors' study was cancellous allograft enriched with bone marrow stem cells, and platelet-rich plasma and its growth factors. ${ }^{20,21}$

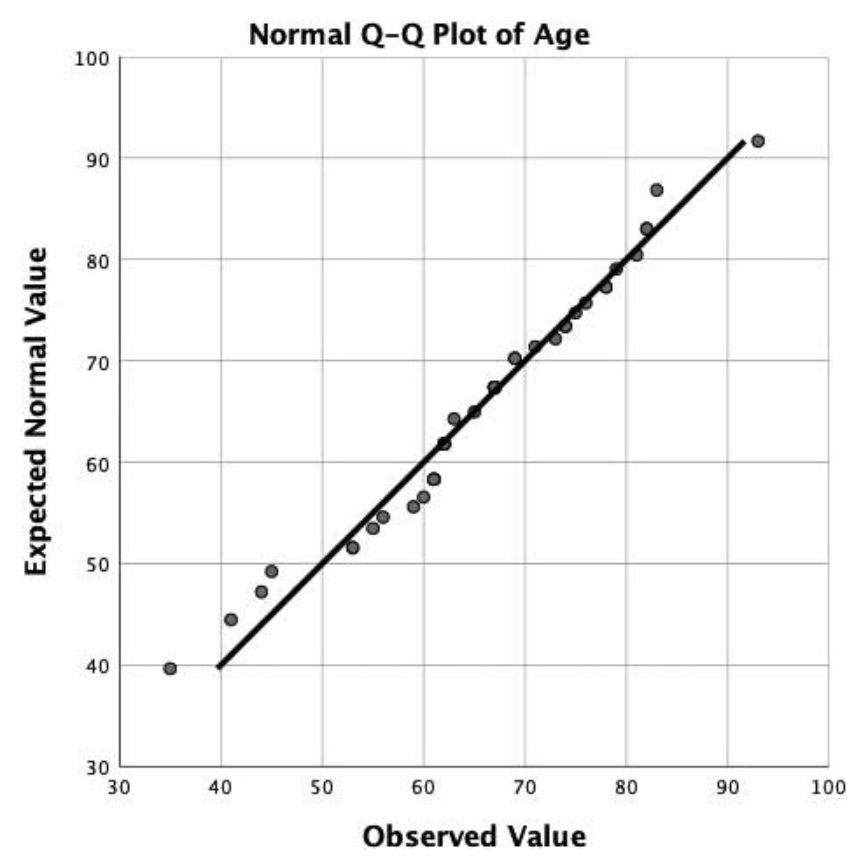

Figure 2. The quantile-quantile plot of the endoscopy patients' age shows normal distribution. The average age was $65.66 \pm 11.90$ years SD, ranging from 35 to 93 years.

\section{MATERIALS AND METHODS}

Our study included 43 patients who underwent endoscopically assisted MIS-TLIF in our clinic between 2010 and 2013. Preoperatively, each patient's functioning was assessed using the Oswestry Disability Index (ODI) ${ }^{2-24}$ and the visual analog scale (VAS) score for back and leg pain. ${ }^{25}$ Postoperatively, patients were evaluated at 1 month, 3 months, 1 year, and 2 years. This retrospective study consisted of groups of consecutive patients seen in the clinics of the participating study sites. All patients provided informed consent. The total study population consisted of $23(53.5 \%)$ females and 20 $(46.5 \%)$ males. The mean follow-up was 22.5 months, ranging from 3 to 42 months. The patients' ages ranged from 35 to 93 years with a mean age of 65.65 years ( $\mathrm{SD}=11.90$ years) with a nearly normal distribution (Figures 1 and 2). The inclusion and exclusion criteria for this study have been published elsewhere in detail and are briefly described in the following. ${ }^{26,27}$ The following criteria were used to determine patient inclusion:

(1) symptomatic lumbar radiculopathy, dysesthesias, or decreased motor function,

(2) lumbar magnetic resonance imaging (MRI) showing central, foraminal, lateral recess, or extraforaminal stenosis, 
(3) more than $4 \mathrm{~mm}$ of translational motion on dynamic/extension flexion views suggesting unstable spondylolisthesis, and

(4) unrelenting pain, in spite of physical therapy, nonsteroidal anti-inflammatories, and transforaminal epidural steroid injections for a minimum 8 weeks.

The following exclusion criteria were employed:

(1) metastatic disease,

(2) infection,

(3) acute extruded disc herniation, or

(4) surgical procedures on the cervical or lumbar spine, or other pain management procedures such as implantation of pain stimulators.

\section{Preoperative Imaging and Planning}

For preoperative imaging, the authors mandated that patients present with lumbar MRI and standing dynamic flexion and extension radiographs. Typically, these routine studies show the extent and presence of instability of the diseased symptomatic spinal level contemplated for surgery. Occasionally, the authors requested computed tomography (CT) scans when extensive facet arthropathy or other obstacles to the foraminal access were suspected. As listed in the inclusion and exclusion criteria, patients and their imaging studies were also assessed for obstructing spinal deformity when considering them for the endoscopically assisted MIS-TLIF. Also, the pedicle diameter, length, and orientation, as well as the diagonal length and surface area of the vertebral endplate available for the intended cage and screw implantation were routinely measured on axial and sagittal views. The size and orientation of the facet joints were also regularly recorded, particularly if transfacet screw fixation was contemplated. Careful assessment of spinal stenosis in the central canal and the lateral recess of the surgical levels was done by employing several validated and published radiographic classification systems. ${ }^{28-33}$

\section{Patient Positioning and Anesthesia}

For the endoscopically assisted MIS-TLIF, the patient is positioned prone (Figure 3). The authors and their respective anesthesia teams have deployed a monitored anesthesia care (MAC) protocol, which uses a continuous infusion of dexmedetomidine (Precedex) and propofol for conscious sedation and

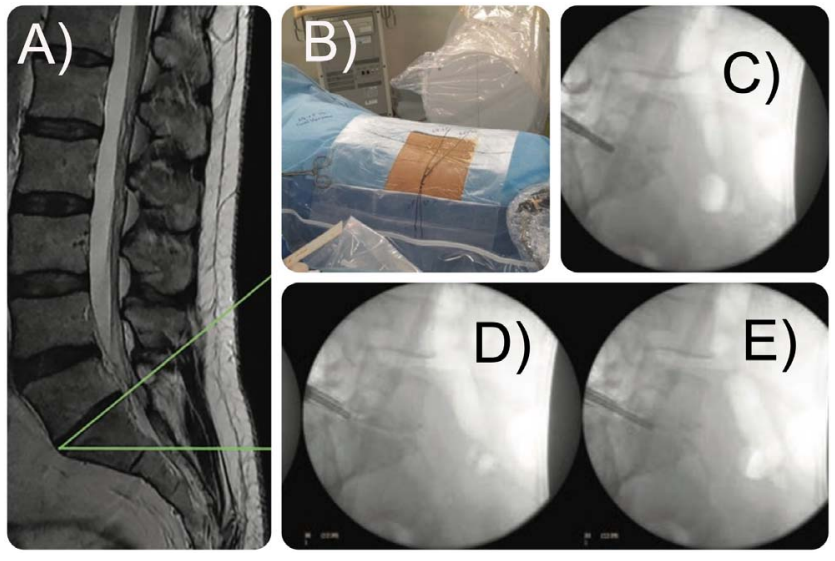

Figure 3. An exemplary case of a 63-year-old female patient who underwent endoscopically assisted minimally invasive surgery with transforaminal lumbar interbody fusion. Shown is $(A)$ the preoperative sagittal MRI scan showing the sacral slope, $(B)$ positioning and draping of the patient, and (C-E) various steps of the transforaminal interspace preparation with (C) reamers, (D) Kerrison, and (E) chisels.

allows the surgeon to communicate with the patient when needed verbally. ${ }^{34-38}$ In addition, the surgeon injects local anesthetic, using 2\% lidocaine for skin anesthesia and $1 \%$ lidocaine into the muscular working tract. Local anesthesia employed in such way decreases the painful stimulus during the procedure and simplifies the medical anesthesia, aiming to keep the patient at a sedation level commensurate with a level 3 on the Ramsay scale, which has been reported to achieve better anxiolysis and intra- and postoperative analgesia. ${ }^{39}$

\section{Posterior Decompression}

In cases with central canal stenosis, the endoscopically assisted MIS-TLIF surgery starts with placement of progressive dilators and tubular retractors of up to $13 \mathrm{~mm}$ directly onto the pedicle on the approach side. The decompression commences with a proximal hemilaminectomy, then a hemifacetectomy followed by a distal hemilaminectomy. Dissection of the ligamentum flavum is performed to achieve complete decompression of neural structures and exposure of the intervertebral disc. The tubular retractor can be repositioned at different angles, effectively creating an inverted cone access corridor through a small skin incision. This single unilateral skin incision can also be used for contralateral nerve root decompression if needed by tilting the tubular retractors medially and across the midline. The authors' personal preference is not to fix the tubular retractors and to perform a freehand technique. In cases where symptoms are bilateral, a contralateral approach 
with tubular retractors can be achieved. In some patients in this study, the authors employed the full-endoscopic decompression whenever the extent of central canal decompression necessary would not prolong the surgery unduly since the patients were awake.

\section{Transforaminal Surgery}

A 7-mm working cannula is placed into the surgical neuroforamen after serial dilation. Both authors use a $20^{\circ}$ high-definition foraminoscope. The working cannula has a $45^{\circ}$ bevel allowing use of its tip as a nerve root retractor and exposing a much larger surgical area than dictated by its diameter. Depending on the patient's body habitus, the incision is made 8 to $12 \mathrm{~cm}$ from the midline while allowing parallel access to the surgical disc interspace (Figure 4). The authors perform their modified form of the outside-in technique originally popularized by Hoogland et al. ${ }^{40-45}$ An initial foraminoplasty is performed to achieve proper decompression and release of both exiting and traversing nerve roots, with 2 principal goals: to decrease compressive symptoms and to enable cage and allograft entry into the intervertebral space. Typically, the decompression begins on the facet joint toward the pars interarticularis, releasing the exiting nerve root, and concluding on the caudal pedicle, releasing the traversing nerve root. The endoscopic decompression allows a wide foraminoplasty and dramatically improves access to the now-exposed intervertebral disk. The endoscope and interbody fusion instruments are freely movable in both the axial and the sagittal plane. Nerve roots must be visualized with a pulsatile dura and proper coloration.

\section{Instruments}

Instruments found useful to extract protruded or extruded disk fragments include graspers and punches. A thorough discectomy is of utmost importance as disc material left behind could be pushed into the central canal or lateral recess contributing to failure of pain relief. The vertebral endplates are prepared using 4-mm round drill bits, reamers, and trephines for endplate eburnation and aiming to produce punctate bleeding spots with the intent to stimulate bone formation and to facilitate successful fusion. Tissue dissection and control of bleeding may be achieved employing bipolar radiofrequency applications. ${ }^{46}$

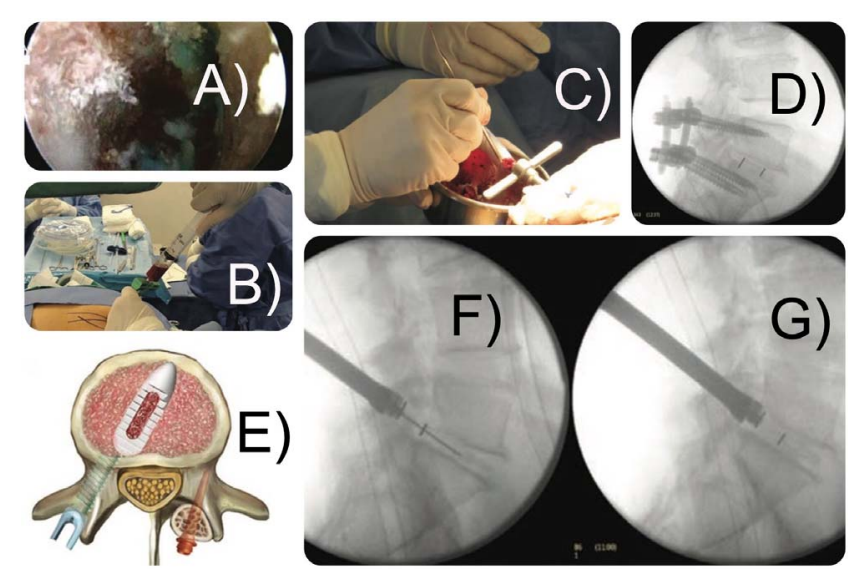

Figure 4. Intraoperative steps of the fusion surgery of the patient shown in Figure 3 showing the $(A)$ endoscopic view of the decorticated endplates and the empty interspace, (B) the aspiration of bone marrow, $(C)$ the enrichment of allograft chips with bone marrow aspirate and placement through a funnel into the intervertebral disc space, (D) the posterior supplemental percutaneously placed pedicle screw system, (E) the oblique bullet-nosed cannulated interbody fusion cage placed over a nitinol guidewire into the $(F)$ intervertebral disc space into its $(G)$ final position under fluoroscopic control.

\section{Tips and Pearls for Endoscopic L5-S1 MIS-TLIF}

A high iliac crest can obstruct trocar passage to the L5-S1 disk. Occasionally, a wide ilial opening angle due to a low-riding ilium allows access to this level. The disc obliquity is another crucial factor to take into consideration. A horizontal disc typically aligns at an acute angle to the endoscopic working channel, thus making cage insertion about an acute angle of a short distance into the disc space somewhat tricky. The authors followed the radiographic assessment protocol described by Patgaonkar et $\mathrm{al}^{47}$ to assess the risk of not being able to insert a large cage transforaminally. Additional problems may arise from hypertrophic facets that may need initial manual foraminoplasty with handheld reamers, drills, and trephines before motorized burrs are inserted through the endoscope's inner working channel to perform the rest of the introitus and endplate preparation for the cage under direct visualization. Typically, the endoscope is best deployed in releasing the exiting nerve root from tethering or bony and soft tissue compression, thus allowing the surgeon to mobilize it, expose the triangular safe zone, and reach the intervertebral space. This preoperative planning is time well spent. $^{48}$

\section{Bone Graft and Biologics}

As an interbody fusion graft, the authors employ cancellous allograft chips enriched with bone marrow concentrate and activated platelet-derived 
growth factor, which has been reported to achieve fusion rates comparable to autograft (Figure 4). Approximately $30 \mathrm{~mL}$ of autologous bone marrow was extracted from the patient's iliac crest using 2 syringes; bone marrow typically contained an average of $\sim 200,000 / \mu \mathrm{L}$ known to release growth factors including platelet-derived growth factor, transforming growth factor- $\beta$, vascular endothelial growth factor, and others. ${ }^{20,21}$

\section{Cage Measurement, Bone Allograft, and Cage Placement}

A cage sizing tool is positioned in the intervertebral space to measure the intervertebral cage size that will be employed. Depending on the patient's anatomy, approximately $10 \mathrm{~mL}$ of bone allograft mixed with bone marrow concentrate and plateletderived growth factors are impacted on the anterior and lateral areas of the intervertebral space while leaving enough space for placement of the cage, whose position is checked on posteroanterior and lateral intraoperative fluoroscopic views. The neuroforamen is inspected and cleaned of any bone graft material that may have extruded from the interspace after the cage insertion. The authors aim for an oblique cage position in an approximate $45^{\circ}$ angle relative to the posterior annulus across the interspace to achieve maximum footprint and optimized anterior column support. Packing of the cage should also be maximized to improve bony fusion through the implant and minimize cage subsidence.

\section{Posterior Supplemental Fixation}

For the posterior supplemental fixation, a Jamshid needle is placed percutaneously into the target pedicle under fluoroscopic control. The pedicle screws are inserted over guide wires after the tapping. Rods are placed percutaneously to complete the posterior construct. Transverse processes are decorticated and additional bone graft placed into the posterolateral gutter. While most patients had a bilateral pedicle screw construct, some patients underwent unilateral pedicle screw placement and contralateral transfacet screw fixation ${ }^{49}$ using established techniques to simplify the surgery. ${ }^{50,51}$

\section{Fusion and Outcome Analysis}

For the clinical outcome analysis, descriptive statistics (mean and SD), cross-tabulation statistics,
Table 1. Preoperative diagnosis, spondylolisthesis, and stenosis grading.

\begin{tabular}{|c|c|c|c|c|}
\hline & Frequency & $\%$ & $\begin{array}{l}\text { Valid } \\
\%\end{array}$ & $\begin{array}{c}\text { Cumulative } \\
\%\end{array}$ \\
\hline \multicolumn{5}{|l|}{ Preoperative diagnosis } \\
\hline Spondyolisthesis & 23 & 53.5 & 53.5 & 53.5 \\
\hline Stenosis & 20 & 46.5 & 46.5 & 100.0 \\
\hline Total & 43 & 100.0 & 100.0 & \\
\hline \multicolumn{5}{|c|}{$\begin{array}{l}\text { Spondolisthesis Meyerding } \\
\text { grade }\end{array}$} \\
\hline No spondolisthesis & 20 & 46.5 & 46.5 & 46.5 \\
\hline Grade I & 22 & 51.2 & 51.2 & 97.7 \\
\hline Grade II & 1 & 2.3 & 2.3 & 100.0 \\
\hline Total & 43 & 100.0 & 100.0 & \\
\hline \multicolumn{5}{|l|}{ Central canal stenosis } \\
\hline$<100 \mathrm{~mm}^{2}$ & 39 & 90.7 & 90.7 & 90.7 \\
\hline$>100 \mathrm{~mm}^{2}$ & 4 & 9.3 & 9.3 & 100.0 \\
\hline Total & 43 & 100.0 & 100.0 & \\
\hline \multicolumn{5}{|l|}{ Levels } \\
\hline L3-4 & 7 & 16.3 & 16.3 & 16.3 \\
\hline L4-5 & 29 & 67.4 & 67.4 & 83.7 \\
\hline L5-S1 & 7 & 16.3 & 16.3 & 100.0 \\
\hline Total & 43 & 100.0 & 100.0 & \\
\hline
\end{tabular}

and measures of association were computed for 2way tables using IBM SPSS Statistics software, Version 25.0. The Pearson $\chi^{2}$ and the likelihoodratio $\chi^{2}$ tests were used as statistical measures of association. The ODI ${ }^{23,24}$ and VAS leg scores ${ }^{25}$ were recorded preoperatively, within 6 weeks postoperatively from the index surgery, and at final follow-up. The interbody fusion was assessed using the Bridwell classification: grade I, segment fused with remodeling and trabeculae present; grade II, graft intact, not fully remodeled and incorporated but no lucency present; grade III, graft intact, potential lucency present at top and bottom of graft; and grade IV, fusion absent with collapse or resorption of the graft.

\section{RESULTS}

A breakdown of the preoperative diagnoses revealed that $23(53.5 \%)$ of the 43 patients underwent endoscopically assisted MIS-TLIF for spondylolisthesis, and the remaining 20 (46.5\%) patients had severe stenosis in the spinal canal, lateral recesses, and neuroforamina (Table 1). The indication for stabilization with MIS-TLIF was iatrogenic decompression-induced instability. Only 1 patient $(1 / 43 ; 2.3 \%)$ had a grade 2 anterolisthesis using the Meyerding scale. The vast majority (22/43; $51.2 \%$ ) had grade 1 anterolisthesis with associated lateral recess and foraminal stenosis. Severe central canal stenosis $\left(<100 \mathrm{~mm}^{2}\right)$ was observed in 4 patients $(9.3 \%)$, and 39 patients had surgery for predominately lateral recess and foraminal stenosis due to herniated disc and degenerative facet disease. 
Endoscopic TLIF With PEEK and Posterior Supplemental Fixation

Table 2. Risk factors that could affect fusion rate and clinical outcome.

\begin{tabular}{|c|c|c|c|c|}
\hline & Frequency & $\%$ & $\begin{array}{l}\text { Valid } \\
\%\end{array}$ & $\begin{array}{c}\text { Cumulative } \\
\%\end{array}$ \\
\hline \multicolumn{5}{|l|}{ Spinal risk factor } \\
\hline None & 22 & 51.2 & 51.2 & 51.2 \\
\hline $\begin{array}{l}\text { Adjacent segment } \\
\text { herniated disc }\end{array}$ & 1 & 2.3 & 2.3 & 53.5 \\
\hline Deformity & 2 & 4.7 & 4.7 & 58.1 \\
\hline Multilevel disease & 5 & 11.6 & 11.6 & 69.8 \\
\hline Osteoporosis & 9 & 20.9 & 20.9 & 90.7 \\
\hline $\begin{array}{l}\text { Previous spinal } \\
\text { decompression }\end{array}$ & 3 & 7.0 & 7.0 & 97.7 \\
\hline Previous spinal fusion & 1 & 2.3 & 2.3 & 100.0 \\
\hline Total & 43 & 100.0 & 100.0 & \\
\hline \multicolumn{5}{|l|}{ Medical risk factor } \\
\hline None & 35 & 81.4 & 81.4 & 81.4 \\
\hline Diabetes & 1 & 2.3 & 2.3 & 83.7 \\
\hline Heart disease & 7 & 16.3 & 16.3 & 100.0 \\
\hline Total & 43 & 100.0 & 100.0 & \\
\hline \multicolumn{5}{|l|}{ Body mass index } \\
\hline$<25$ & 2 & 4.7 & 4.7 & 4.7 \\
\hline $25-30$ & 20 & 46.5 & 46.5 & 51.2 \\
\hline $30-35$ & 21 & 48.8 & 48.8 & 100.0 \\
\hline Total & 43 & 100.0 & 100.0 & \\
\hline \multicolumn{5}{|l|}{ Social risk factors } \\
\hline None & 39 & 90.7 & 90.7 & 90.7 \\
\hline Alcohol abuse & 1 & 2.3 & 2.3 & 93.0 \\
\hline Psychiatric history & 2 & 4.7 & 4.7 & 97.7 \\
\hline Smoking & 1 & 2.3 & 2.3 & 100.0 \\
\hline Total & 43 & 100.0 & 100.0 & \\
\hline
\end{tabular}

Each of the 43 patients underwent a single-level endoscopically assisted MIS-TLIF. The frequency distribution analysis of the surgical levels showed that as expected, the L4-5 level was the most commonly operated spinal motion segment (29/43; $67.4 \%$ ). The remaining 14 patients were equally distributed, with 7 patients $(16.3 \%)$ having had surgery at L3-4 and another 7 patients $(16.3 \%)$ at the L5-S1 level.

The authors analyzed the medical risk factors and risk factors related to preexisting spine disease or prior surgery, as it could impact the clinical outcome analysis in this study. Twenty-two $(51.2 \%)$ of study patients had no such risk factors (Table 2). The most common potential risk factors were osteoporosis $(9 / 43 ; 20.9 \%)$, heart disease $(7 / 43$; $16.3 \%)$, multilevel disease $(5 / 43 ; 11.6 \%)$, and previous spinal decompression surgery $(3 / 43 ; 7 \%)$. Nearly half of the patients $(21 / 43 ; 48.8 \%)$ were obese with a body mass index from 30 to 35 . The

Table 3. Macnab outcomes.

\begin{tabular}{lcrrr}
\hline & Frequency & \multicolumn{1}{c}{ \% } & \multicolumn{1}{c}{$\begin{array}{c}\text { Valid } \\
\mathbf{\%}\end{array}$} & $\begin{array}{c}\text { Cumulative } \\
\mathbf{\%}\end{array}$ \\
\hline Excellent & 8 & 18.6 & 18.6 & 18.6 \\
Fair & 4 & 9.3 & 9.3 & 27.9 \\
Good & 31 & 72.1 & 72.1 & 100.0 \\
Total & 43 & 100.0 & 100.0 & \\
\hline
\end{tabular}

Table 4. Descriptive VAS back, VAS leg, and ODI statistics.

\begin{tabular}{lcccc}
\hline & Minimum & Maximum & Mean & SD \\
\hline Preop VAS back & 7.00 & 10.00 & 8.9070 & .81105 \\
Postop VAS back & 1.00 & 8.00 & 3.8605 & 1.69848 \\
Final VAS back & 1.00 & 8.00 & 2.7674 & 1.58621 \\
Preop VAS leg & 3 & 8 & 5.58 & 1.340 \\
Postop VAS leg & 1 & 7 & 2.16 & 1.331 \\
Final VAS leg & 1 & 4 & 1.67 & .739 \\
Preop ODI & 32.00 & 78.00 & 54.3721 & 12.36936 \\
Postop ODI & 0.00 & 60.00 & 23.3488 & 12.63194 \\
Final ODI & 4.00 & 62.00 & 18.4651 & 12.12504 \\
Valid N (list-wise) & 43 & & & \\
\hline
\end{tabular}

Abbreviations: VAS, visual analog scale; ODI, Oswestry Disability Index.

majority of patients $(90.7 \%)$ had excellent $(8 ; 43$; $18.6 \%)$ or good $(31 / 43 ; 72.1 \%)$ Macnab outcomes (Tables 3-5). Only 4 patients $(9.3 \%)$ had fair Macnab outcomes. The across-the-board analysis of primary outcome measures showed statistically significant reductions on paired $t$ testing from the average preoperative VAS back scores of 8.9070 to a postoperative VAS score of 3.8605, and a score of 2.7674 at final follow-up $(P<.0001)$. The reductions in VAS leg scores were also significant from preoperative score of 5.58 to 2.16 postoperatively, and a final follow-up score of $1.67(P<.0001)$. There were also statistically significant reductions in the ODI score from a preoperative value of 54.4 to 23.3 postoperatively and 18.5 at the final follow-up $(P<.0001)$. The cross-tabulation of fusion grades versus clinical outcome shows a significant correlation with successful interbody fusion and excellent and good Macnab outcomes $(P=.027$; Tables 6 and $7)$. The vast majority of patients $(92.9 \%)$ with Bridwell grade I fusion had excellent or good Macnab outcomes (Figure 5 and 6).

The overall complication rate was $11 \%(5 / 46)$ and the reoperation rate of $3.5 \%(3 / 46)$. One patient suffered from a postoperative foot drop due to L5 neuropraxia after surgery at the L5-S1 level. Ultimately, the patient recovered function and rated his clinical outcome as excellent at the final followup. In another patient, facet-pedicular screws had to be converted to a nonsegmental pedicle screw construct due to loosening. An additional patient had an asymptomatic medially placed pedicle screw revealed on a postoperative CT scan. The patient underwent revision surgery within 12 hours to reposition the pedicle screw. A dural tear was encountered in one patient and was treated with a collagen patch (Duragen). The patient was discharged after 24 hours and was advised to observe an additional 5 days of bed rest at home. This patient had an otherwise uncomplicated recovery 
Table 5. Paired $t$ test VAS back, VAS leg, and ODI scores.

\begin{tabular}{|c|c|c|c|c|c|c|c|c|}
\hline \multirow[b]{2}{*}{ Pairs } & \multirow[b]{2}{*}{ Mean } & \multirow[b]{2}{*}{ SD } & \multirow[b]{2}{*}{ SEM } & \multicolumn{2}{|c|}{$\begin{array}{l}95 \% \text { Confidence } \\
\text { Interval of Difference }\end{array}$} & \multirow[b]{2}{*}{$t$} & \multirow[b]{2}{*}{$d f$} & \multirow{2}{*}{$\begin{array}{l}\text { Significance } \\
\text { (2-tailed) }\end{array}$} \\
\hline & & & & Lower & Upper & & & \\
\hline Preop-postop VAS back & 5.04651 & 1.495 & .228 & 4.586 & 5.506 & 22.131 & 42 & .000 \\
\hline Preop-final VAS back & 6.13953 & 1.626 & .2481 & 5.638 & 6.640 & 24.747 & 42 & .000 \\
\hline Preop-postop VAS leg & 3.422 & 1.323 & .197 & 3.025 & 3.820 & 17.356 & 44 & .000 \\
\hline Preop-final VAS leg & 3.911 & 1.145 & .171 & 3.567 & 4.255 & 22.922 & 44 & .000 \\
\hline Preop-postop ODI & 31.02326 & 13.103 & 1.998 & 26.990 & 35.055 & 15.526 & 42 & .000 \\
\hline Preop-final ODI & 35.90698 & 15.862 & 2.418 & 31.025 & 40.788 & 14.844 & 42 & .000 \\
\hline
\end{tabular}

Abbreviations: VAS, visual analog scale; ODI, Oswestry Disability Index.

without headaches or the development of a cerebrospinal fluid fistula. One patient was suspected of having developed postoperative discitis. His postoperative MRI scan prompted by acute onset of back pain showed high signal intensity in the surgical disc and endplates, but the patient's white blood cell count was normal. Exploration with an excisional biopsy sent for cultures did not reveal an infection. The patient was treated for aseptic discitis with analgesics and a lumbar corset.

\section{DISCUSSION}

The endoscopically assisted MIS-TLIF is an example of the hybridization of endoscopic spinal surgery techniques with traditional and minimally invasive spinal fusion surgery, a strategy which is at the center of this special focus issue of the International Journal of Spine Surgery on modern endoscopy applications. It combines elements of TLIF, microsurgical tubular retractor decompression surgery, and percutaneous pedicle screw and transfacet fixation. Most of these techniques are

Table 6. Cross-tabulation of fusion grade according to Bridwell classification and clinical Macnab outcomes.

\begin{tabular}{lccccc}
\hline & \multicolumn{4}{c}{ Bridwell Fusion Grade } & \\
\cline { 2 - 4 } Macnab & B1 & B2 & B3 & B4 & Total \\
\hline $\begin{array}{l}\text { Excellent } \\
\text { Count }\end{array}$ & 7 & 0 & 0 & 1 & 8 \\
\% within Macnab & 87.5 & 0.0 & 0.0 & 12.5 & 100.0 \\
$\quad$ \% within Bridwell & 25.0 & 0.0 & 0.0 & 50.0 & 18.6 \\
Fair & & & & & \\
$\quad$ Count & 2 & 0 & 1 & 1 & 4 \\
\% within Macnab & 50.0 & 0.0 & 25.0 & 25.0 & 100.0 \\
\% within Bridwell & 7.1 & 0.0 & 25.0 & 50.0 & 9.3 \\
Good & & & & & \\
$\quad$ Count & 19 & 9 & 3 & 0 & 31 \\
$\quad \%$ within Macnab & 61.3 & 29.0 & 9.7 & 0.0 & 100.0 \\
$\quad$ \% within Bridwell & 67.9 & 100.0 & 75.0 & 0.0 & 72.1 \\
Total & & & & & \\
$\quad$ Count & 28 & 9 & 4 & 2 & 43 \\
$\quad$ \% within Macnab & 65.1 & 20.9 & 9.3 & 4.7 & 100.0 \\
\% within Bridwell & 100.0 & 100.0 & 100.0 & 100.0 & 100.0 \\
\hline
\end{tabular}

time-proven with their benefit demonstrated in the literature in terms of minimizing tissue trauma from the surgical access to the diseased lumbar spinal motion segment. ${ }^{52-55}$ Long-term clinical outcomes are considered mainly equivalent to contemporary MIS implants and surgical techniques. The question arises: Why the combination with endoscopic spinal surgery $?^{56}$ The answer to this question may not be obvious to some but is buried in the details of the surgeon and patient preferences and an overall trend to outpatient spinal surgery. While the latter may not be a motivation in countries where hospital admissions are commonplace, simplifying spine care is on the radar of many public healthcare systems that support transitioning spine surgeries into ambulatory surgery centers. ${ }^{57}$ Ultimately, replacing traditional open spine surgeries with these simplified spine care procedures for common painful degenerative conditions of the spine is expected by many, and the financial incentives ${ }^{58}$ are clearly positioned in such a way to promote this trend. ${ }^{59-61}$ The endoscopic-assisted MIS-TLIF where a static cannulated cage is introduced into the intervertebral disc space that has been prepared under direct visualization over a nitinol guidewire is a stepping stone towards such simplified lumbar decompression fusion procedure that is ultimately less burdensome to the patient ${ }^{62,63}$ and conserves resources to take care of the many patients who are coming onto the healthcare rolls in their advanced age. ${ }^{32,62,64}$

In this study, the authors have demonstrated the feasibility of performing a circumferential fusion

Table 7. $\chi^{2}$ tests for Bridwell classification and clinical Macnab outcomes.

\begin{tabular}{lccc}
\hline & Value & $\boldsymbol{d f}$ & $\begin{array}{c}\text { Asymptotic Significance } \\
\text { (2-sided) }\end{array}$ \\
\hline $\begin{array}{l}\text { Pearson } \chi^{2} \\
\text { Likelihood ratio }\end{array}$ & $12.180^{\mathrm{a}}$ & 6 & .058 \\
No. of valid cases & 43.224 & 6 & .027 \\
& & & \\
${ }^{\mathrm{a}}$ Nine cells $(75.0 \%)$ & have expected count of less than 5. The minimum expected \\
count is .19.
\end{tabular}




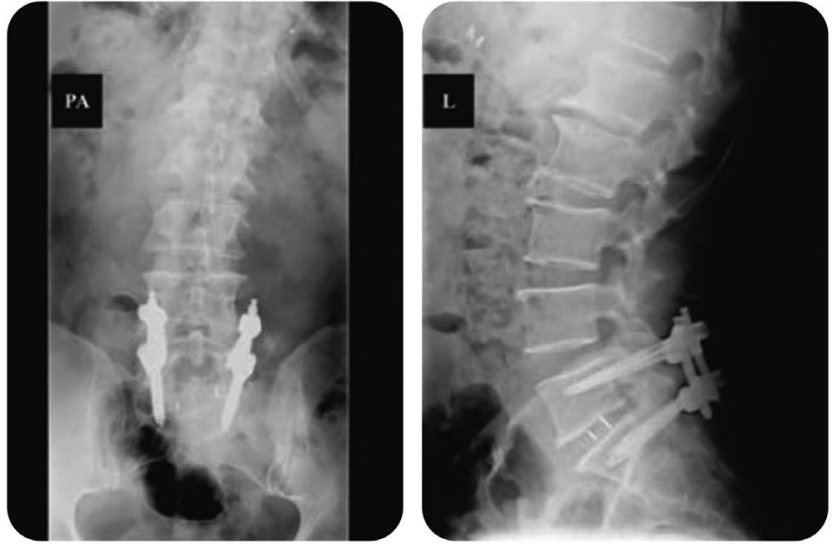

Figure 5. Postoperative posteroanterior and lateral standing $x$-rays of the same 63-year-old female patient illustrated in Figures 2 and 3 who underwent endoscopically assisted minimally invasive surgery with transforaminal lumbar interbody fusion are shown. These radiographs were taken at 6 weeks postoperatively.

with the placement of an interbody fusion cage and nonsegmental pedicle or transfacet fixation under local anesthesia and sedation using modern MAC protocols. ${ }^{65} \mathrm{MAC}$ is associated with fewer problems related to anesthesia or narcotic-induced postoperative nausea and rapid postoperative recovery by employing the enhanced recovery anesthesia protocols. ${ }^{66-69}$ These protocols, in combination with MAC, have substantially changed how patients are managed during the perioperative period to facilitate the rapid recovery from outpatient spine surgery in ambulatory surgery centers while achieving more effective pain control and rehydration. The authors' methodology also affords the surgeon the ability to communicate with the patient during the operation should the need arise to monitor neurological functioning.

The posterolateral access to the L5-S1 motion segment is of particular significance to developing reliable and feasible outpatient protocols for decompression fusion surgeries at that level. Direct lateral approaches are impractical at that level. Anterior access to the lumbar spine has been demonstrated in ambulatory surgery centers. Still, it is associated with several practical and theoretical disadvantages that may be interpreted differently from one to another surgery center depending on the individual surgeons' skill level, and the available equipment and support systems. ${ }^{70-72}$ There is potential need for an access surgeon, the use of abdominal relaxation to facilitate the anterior exposure may lead to longer wakeup and postoperative urinary retention, and ileus. A traditional translaminar TLIF approach may be an alternative

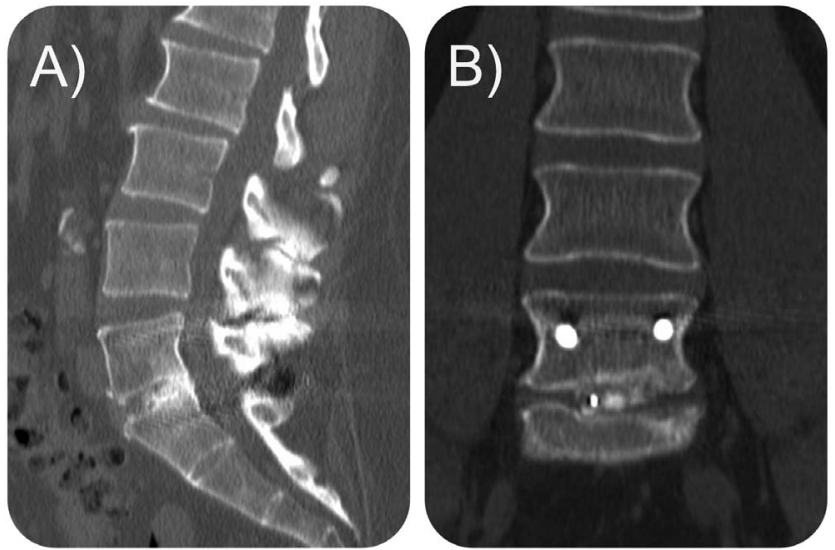

Figure 6. (A) Sagittal and (B) coronal computed tomography (CT) sections of the same 63-year-old female patient illustrated in Figures 2, 3, and 4 who underwent endoscopically assisted minimally invasive surgery with transforaminal lumbar interbody fusion taken 35 months postoperatively. This CT scan was prompted by recurrent back pain without sciatica that was ultimately attributed to adjacent-level painful L4-5 facet arthropathy which was treated successfully without additional surgery and with medical and interventional supportive care measures.

to our endoscopic preparation of the L5-S1 interspace but is often more time consuming and perhaps associated with more bleeding. ${ }^{35,70}$ Assessing the configuration of the iliac crest on the access side and the presence of transitional anatomy or spinal deformity is of particular importance when selecting patients for this type of L5-S1 MISTLIF. ${ }^{47}$ The surgeon's skill level and comfort level with the endoscopic procedure is likely the most relevant factor in the patient eligibility determination. $^{71}$

Another advantage of the endoscopically performed foraminoplasty relates to the direct visualization $^{73,74}$ of the exiting and traversing nerve roots, which are often tethered or adherent to the intervertebral discs or the degenerative facet joint complex via juxtasynovial facet cysts. ${ }^{75}$ The endoscopic release of these nerve roots can be elegantly done with minimal manipulation leading to less irritation of the dorsal root ganglion or traction injury, which was observed in only 1 of our patients with neuropraxia and a foot drop that resolved spontaneously with supportive care measures within 3 months from the index surgery. Direct visualization $^{73}$ of the interspace and the endplates during the discectomy and decortication procedures minimizes excessive violation of the subchondral bone with the intent of providing just enough punctate bleeding to stimulate incorporation of the interbody fusion graft while minimizing the risk of cage subsidence. $^{60,76,77}$ To the authors' surprise, cage subsidence was not an issue in our case series. It perhaps 
was related to the use of a static cage and the careful endoscopically visualized endplate preparation.

\section{CONCLUSIONS}

Based on our experience, the authors recommend the use of an endoscope as an adjunct to MIS-TLIF. Clinical outcomes with the endoscopic interbody fusion procedure with a static PEEK cage in conjunction with platelet-enriched bone allograft were favorable.

\section{REFERENCES}

1. McGirt MJ, Parker SL, Lerner J, Engelhart L, Knight T, Wang MY. Comparative analysis of perioperative surgical site infection after minimally invasive versus open posterior/transforaminal lumbar interbody fusion: analysis of hospital billing and discharge data from 5170 patients. J Neurosurg Spine. 2011;14(6):771-778.

2. Goldstein CL, Macwan K, Sundararajan K, Rampersaud YR. Perioperative outcomes and adverse events of minimally invasive versus open posterior lumbar fusion: meta-analysis and systematic review. J Neurosurg Spine. 2016;24(3):416-427.

3. Sharif S, Afsar A. Learning Curve and Minimally Invasive Spine Surgery. World Neurosurg. 2018;119:472-478.

4. Byvaltsev VA, Kalinin AA, Goloborod'ko VY, Shepelev VV, Pestryakov YY. [Possibilities and advantages of minimally invasive dorsal decompressive-stabilizing interventions in the treatment of degenerative spondylolisthesis of the elderly patients.]. Adv Gerontol. 2019;32(1-2):189-197.

5. Wang H, Huang B, Li C, et al. Learning curve for percutaneous endoscopic lumbar discectomy depending on the surgeon's training level of minimally invasive spine surgery. Clin Neurol Neurosurg. 2013;115(10):1987-1991.

6. Kim J-S, Yeung A, Lokanath YK, Lewandrowski K-U. Is Asia truly a hotspot of contemporary minimally invasive and endoscopic spinal surgery? Journal of Spine Surgery. 2020:S224-S236.

7. Adogwa O, Elsamadicy AA, Han JL, Cheng J, Karikari I, Bagley CA. Do measures of surgical effectiveness at 1 year after lumbar spine surgery accurately predict 2-year outcomes? $J$ Neurosurg Spine. 2016;25(6):689-696.

8. Alvi MA, Kurian SJ, Wahood W, Goyal A, Elder BD, Bydon M. Assessing the Difference in Clinical and Radiologic Outcomes Between Expandable Cage and Nonexpandable Cage Among Patients Undergoing Minimally Invasive Transforaminal Interbody Fusion: A Systematic Review and Meta-Analysis. World Neurosurg. 2019;127:596-606 e591.

9. Choi WS, Kim JS, Ryu KS, Hur JW, Seong JH. Minimally Invasive Transforaminal Lumbar Interbody Fusion at L5-S1 through a Unilateral Approach: Technical Feasibility and Outcomes. Biomed Res Int. 2016;2016:2518394.

10. Kim JS, Kang BU, Lee SH, et al. Mini-transforaminal lumbar interbody fusion versus anterior lumbar interbody fusion augmented by percutaneous pedicle screw fixation: a comparison of surgical outcomes in adult low-grade isthmic spondylolisthesis. J Spinal Disord Tech. 2009;22(2):114-121.

11. Liang Y, Shi W, Jiang C, et al. Clinical outcomes and sagittal alignment of single-level unilateral instrumented transforaminal lumbar interbody fusion with a 4 to 5-year follow-up. Eur Spine J. 2015;24(11):2560-2566.

12. Massie LW, Zakaria HM, Schultz LR, Basheer A, Buraimoh MA, Chang V. Assessment of radiographic and clinical outcomes of an articulating expandable interbody cage in minimally invasive transforaminal lumbar interbody fusion for spondylolisthesis. Neurosurg Focus. 2018;44(1):E8.

13. Min SH, Yoo JS. The clinical and radiological outcomes of multilevel minimally invasive transforaminal lumbar interbody fusion. Eur Spine J. 2013;22(5):1164-1172.

14. Skovrlj B, Belton P, Zarzour H, Qureshi SA. Perioperative outcomes in minimally invasive lumbar spine surgery: A systematic review. World J Orthop. 2015;6(11):996-1005.

15. Kamson S, Lu D, Sampson PD, Zhang Y. FullEndoscopic Lumbar Fusion Outcomes in Patients with Minimal Deformities: A Retrospective Study of Data Collected Between 2011 and 2015. Pain Physician. 2019;22(1):75-88.

16. Hofstetter CP, Shin B, Tsiouris AJ, Elowitz E, Hartl R. Radiographic and clinical outcome after 1- and 2-level transsacral axial interbody fusion: clinical article. J Neurosurg Spine. 2013;19(4):454-463.

17. Lau D, Song Y, Guan Z, La Marca F, Park P. Radiological outcomes of static vs expandable titanium cages after corpectomy: a retrospective cohort analysis of subsidence. Neurosurgery. 2013;72(4):529-539; discussion 528-529.

18. Ramirez Leon JF, Ardila AS, Rugeles Ortiz JG, et al. Standalone lordotic endoscopic wedge lumbar interbody fusion (LEW-LIF) with a threaded cylindrical peek cage: report of two cases. J Spine Surg. 2020;6(Suppl 1):S275-S284.

19. Yang Y, Liu B, Rong LM, et al. Microendoscopyassisted minimally invasive transforaminal lumbar interbody fusion for lumbar degenerative disease: short-term and medium-term outcomes. Int J Clin Exp Med. 2015;8(11):2131921326.

20. Feiz-Erfan I, Harrigan M, Sonntag VK, Harrington TR. Effect of autologous platelet gel on early and late graft fusion in anterior cervical spine surgery. $J$ Neurosurg Spine. 2007;7(5):496-502.

21. Vavken J, Vavken P, Mameghani A, Camathias C, Schaeren S. Platelet concentrates in spine fusion: meta-analysis of union rates and complications in controlled trials. Eur Spine J. 2016;25(5):1474-1483.

22. Asher AL, Chotai S, Devin CJ, et al. Inadequacy of 3month Oswestry Disability Index outcome for assessing individual longer-term patient experience after lumbar spine surgery. J Neurosurg Spine. 2016;25(2):170-180.

23. Fairbank J. Use of Oswestry Disability Index (ODI). Spine (Phila Pa 1976). 1995;20(13):1535-1537.

24. Fairbank JC, Pynsent PB. The Oswestry Disability Index. Spine (Phila Pa 1976). 2000;25(22):2940-2952; discussion 2952.

25. Reed CC, Wolf WA, Cotton CC, Dellon ES. A visual analogue scale and a Likert scale are simple and responsive tools for assessing dysphagia in eosinophilic oesophagitis. Aliment Pharmacol Ther. 2017;45(11):1443-1448.

26. Yeung A, Lewandrowski KU. Five-year clinical outcomes with endoscopic transforaminal foraminoplasty for symptomatic degenerative conditions of the lumbar spine: a comparative study of inside-out versus outside-in techniques. $J$ Spine Surg. 2020;6(Suppl 1):S66-S83. 
27. Yeung A, Roberts A, Zhu L, Qi L, Zhang J, Lewandrowski KU. Treatment of Soft Tissue and Bony Spinal Stenosis by a Visualized Endoscopic Transforaminal Technique Under Local Anesthesia. Neurospine. 2019;16(1):52-62.

28. Lee CK, Rauschning W, Glenn W. Lateral lumbar spinal canal stenosis: classification, pathologic anatomy and surgical decompression. Spine (Phila Pa 1976). 1988;13(3):313-320.

29. Lee S, Kim SK, Lee SH, et al. Percutaneous endoscopic lumbar discectomy for migrated disc herniation: classification of disc migration and surgical approaches. Eur Spine J. 2007;16(3):431-437.

30. Lewandrowski KU. "Outside-in" technique, clinical results, and indications with transforaminal lumbar endoscopic surgery: a retrospective study on 220 patients on applied radiographic classification of foraminal spinal stenosis. Int $J$ Spine Surg. 2014;8.

31. Milette PC. Classification, diagnostic imaging, and imaging characterization of a lumbar herniated disk. Radiol Clin North Am. 2000;38(6):1267-1292.

32. Sengupta DK, Herkowitz HN. Lumbar spinal stenosis. Treatment strategies and indications for surgery. Orthop Clin North Am. 2003;34(2):281-295.

33. Hasegawa T, An HS, Haughton VM, Nowicki BH. Lumbar foraminal stenosis: critical heights of the intervertebral discs and foramina. A cryomicrotome study in cadavera. $J$ Bone Joint Surg Am. 1995;77(1):32-38.

34. Choi G, Prada N, Modi HN, Vasavada NB, Kim JS, Lee $\mathrm{SH}$. Percutaneous endoscopic lumbar herniectomy for highgrade down-migrated L4-L5 disc through an L5-S1 interlaminar approach: a technical note. Minim Invasive Neurosurg. 2010;53(3):147-152.

35. Dowling A, Lewandrowski KU, da Silva FHP, Parra JAA, Portillo DM, Gimenez YCP. Patient selection protocols for endoscopic transforaminal, interlaminar, and translaminar decompression of lumbar spinal stenosis. J Spine Surg. 2020;6(Suppl 1):S120-S132.

36. Fujii Y, Yamashita K, Sugiura K, et al. Early return to activity after minimally invasive full endoscopic decompression surgery in medical doctors. Journal of Spine Surgery. 2019:S294-S299.

37. Zhang J, Jin MR, Zhao TX, et al. [Clinical application of percutaneous transforaminal endoscope-assisted lumbar interbody fusion]. Zhongguo Gu Shang. 2019;32(12):1138-1143.

38. Berkenstadt H, Perel A, Hadani M, Unofrievich I, Ram Z. Monitored anesthesia care using remifentanil and propofol for awake craniotomy. J Neurosurg Anesthesiol. 2001;13(3):246-249.

39. Avci S, Bayram B, Inanc G, et al. Evaluation of the compliance between EEG monitoring (Bispectral IndexTM) and Ramsey Sedation Scale to measure the depth of sedation in the patients who underwent procedural sedation and analgesia in the emergency department. Ulus Travma Acil Cerrahi Derg. 2019;25(5):447-452.

40. Hoogland T, van den Brekel-Dijkstra K, Schubert M, Miklitz B. Endoscopic transforaminal discectomy for recurrent lumbar disc herniation: a prospective, cohort evaluation of 262 consecutive cases. Spine (Phila Pa 1976). 2008;33(9):973-978.

41. Schubert M, Hoogland T. Endoscopic transforaminal nucleotomy with foraminoplasty for lumbar disk herniation. Oper Orthop Traumatol. 2005;17(6):641-661.

42. Hoogland T, Scheckenbach C. Low-dose chemonucleol- ysis combined with percutaneous nucleotomy in herniated cervical disks. J Spinal Disord. 1995;8(3):228-232.

43. Hoogland T. Percutaneous endoscopic discectomy. $J$ Neurosurg. 1993;79(6):967-968.

44. Hoogland T, Scheckenbach C. [Percutaneous lumbar nucleotomy with low-dose chymopapain, an ambulatory procedure]. Z Orthop Ihre Grenzgeb. 1995;133(2):106-113.

45. Hoogland T, Schubert M, Miklitz B, Ramirez A. Transforaminal posterolateral endoscopic discectomy with or without the combination of a low-dose chymopapain: a prospective randomized study in 280 consecutive cases. Spine (Phila Pa 1976). 2006;31(24):E890-897.

46. Beyaz SG, Inanmaz ME, Zengin ES, Ulgen AM. Combined Use of High Radiofrequency Disk Ablation, Annulus Modulation, and Manual Nucleotomy in a Patient with Extruded Disk Herniation. Pain Pract. 2016;16(5):E74-80.

47. Patgaonkar P, Datar G, Agrawal U, et al. Suprailiac versus transiliac approach in transforaminal endoscopic discectomy at L5-S1: a new surgical classification of L5-iliac crest relationship and guidelines for approach. J Spine Surg. 2020;6(Suppl 1):S145-S154.

48. Lonne G, Odegard B, Johnsen LG, Solberg TK, Kvistad KA, Nygaard OP. MRI evaluation of lumbar spinal stenosis: is a rapid visual assessment as good as area measurement? Eur Spine J. 2014;23(6):1320-1324.

49. Zhang J, Pan A, Zhou L, Yu J, Zhang X. Comparison of unilateral pedicle screw fixation and interbody fusion with PEEK cage vs. standalone expandable fusion cage for the treatment of unilateral lumbar disc herniation. Arch Med Sci. 2018;14(6):1432-1438.

50. Sivakumaran R, Uschold TD, Brown MT, Patel NR. Transfacet and Transpedicular Posterior Approaches to Thoracic Disc Herniations: Consecutive Case Series of 24 Patients. World Neurosurg. 2018;120:e921-e931.

51. Trungu S, Pietrantonio A, Forcato S, Tropeano MP, Martino L, Raco A. Transfacet Screw Fixation for the Treatment of Lumbar Spinal Stenosis with Mild Instability: A Preliminary Study. J Neurol Surg A Cent Eur Neurosurg. 2018;79(5):358-364.

52. Kim CW, Doerr TM, Luna IY, et al. Minimally Invasive Transforaminal Lumbar Interbody Fusion Using Expandable Technology: A Clinical and Radiographic Analysis of 50 Patients. World Neurosurg. 2016;90:228-235.

53. Patel AA, Zfass-Mendez M, Lebwohl NH, et al. Minimally Invasive Versus Open Lumbar Fusion: A Comparison of Blood Loss, Surgical Complications, and Hospital Course. Iowa Orthop J. 2015;35:130-134.

54. Parker SL, Mendenhall SK, Shau DN, et al. Minimally invasive versus open transforaminal lumbar interbody fusion for degenerative spondylolisthesis: comparative effectiveness and cost-utility analysis. World Neurosurg. 2014;82(1-2):230 238 .

55. Hockley A, Ge D, Vasquez-Montes D, et al. Minimally Invasive Versus Open Transforaminal Lumbar Interbody Fusion Surgery: An Analysis of Opioids, Nonopioid Analgesics, and Perioperative Characteristics. Global Spine $J$. 2019;9(6):624-629.

56. Rouben D, Casnellie M, Ferguson M. Long-term durability of minimal invasive posterior transforaminal lumbar interbody fusion: a clinical and radiographic follow-up. $J$ Spinal Disord Tech. 2011;24(5):288-296. 
57. Ransom NA, Gollogly S, Lewandrowski KU, Yeung A. Navigating the learning curve of spinal endoscopy as an established traditionally trained spine surgeon. J Spine Surg. 2020;6(Suppl 1):S197-S207.

58. Manchikanti L, Helm Ii S, Singh V, Hirsch JA. Accountable interventional pain management: a collaboration among practitioners, patients, payers, and government. Pain Physician. 2013;16(6):E635-670.

59. Heo DH, Park CK. Clinical results of percutaneous biportal endoscopic lumbar interbody fusion with application of enhanced recovery after surgery. Neurosurg Focus. 2019;46(4):E18.

60. Wang MY, Grossman J. Endoscopic minimally invasive transforaminal interbody fusion without general anesthesia: initial clinical experience with 1-year follow-up. Neurosurg Focus. 2016;40(2):E13.

61. Heo DH, Son SK, Eum JH, Park CK. Fully endoscopic lumbar interbody fusion using a percutaneous unilateral biportal endoscopic technique: technical note and preliminary clinical results. Neurosurg Focus. 2017;43(2):E8.

62. Imajo Y, Taguchi T, Neo M, et al. Complications of spinal surgery for elderly patients with lumbar spinal stenosis in a super-aging country: An analysis of 8033 patients. J Orthop Sci. 2017;22(1):10-15.

63. Lewandrowski KU. Incidence, Management, and Cost of Complications After Transforaminal Endoscopic Decompression Surgery for Lumbar Foraminal and Lateral Recess Stenosis: A Value Proposition for Outpatient Ambulatory Surgery. Int J Spine Surg. 2019;13(1):53-67.

64. Held U, Steurer J, Pichierri G, et al. What is the treatment effect of surgery compared with nonoperative treatment in patients with lumbar spinal stenosis at 1-year follow-up? J Neurosurg Spine. 2019:1-9.

65. Singhal NR, Jones J, Semenova J, et al. Multimodal anesthesia with the addition of methadone is superior to epidural analgesia: A retrospective comparison of intraoperative anesthetic techniques and pain management for 124 pediatric patients undergoing the Nuss procedure. $J$ Pediatr Surg. 2016;51(4):612-616.

66. Huang M, Brusko GD, Borowsky PA, et al. The University of Miami spine surgery ERAS protocol: a review of our journey. Journal of Spine Surgery. 2019:S29-S34.

67. Huang M, Brusko GD, Borowsky PA, et al. The University of Miami spine surgery ERAS protocol: a review of our journey. J Spine Surg. 2020;6(Suppl 1):S29-S34.

68. Wang MY, Chang HK, Grossman J. Reduced acute care costs with the ERAS(R) minimally invasive transforaminal lumbar interbody fusion compared with conventional minimally invasive transforaminal lumbar interbody fusion. Neurosurgery. 2018;83(4):827-834.

69. Wang MY, Tessitore E, Berrington N, Dailey A. Introduction. Enhanced recovery after surgery (ERAS) in spine. Neurosurg Focus. 2019;46(4):E1.

70. Lewandrowski KU, Dowling A, de Carvalho P, et al. Indication And Contraindication Of Endoscopic Transforaminal Lumbar Decompression. World Neurosurg. 2020.

71. Lewandrowski KU, Soriano-Sanchez JA, Zhang X, et al. Surgeon training and clinical implementation of spinal endoscopy in routine practice: results of a global survey. J Spine Surg. 2020;6(Suppl 1):S237-S248.

72. Lohre R, Wang JC, Lewandrowski KU, Goel DP.
Virtual reality in spinal endoscopy: a paradigm shift in education to support spine surgeons. J Spine Surg. 2020;6(Suppl 1):S208-S223.

73. Lewandrowski KU, Leon JFR, Yeung A. Use of "InsideOut" technique for direct visualization of a vacuum vertically unstable intervertebral disc during routine lumbar endoscopic transforaminal decompression-a correlative study of clinical outcomes and the prognostic value of lumbar radiographs. Int $J$ Spine Surg. 2019;13(5):399-414.

74. Tsou PM, Alan Yeung C, Yeung AT. Posterolateral transforaminal selective endoscopic discectomy and thermal annuloplasty for chronic lumbar discogenic pain: a minimal access visualized intradiscal surgical procedure. Spine $J$. 2004;4(5):564-573.

75. Hellinger S, Lewandrowski K-U. Clinical outcomes with endoscopic resection of lumbar extradural cysts. Journal of Spine Surgery. 2019:S133-S144.

76. Kim JE, Choi DJ. Biportal endoscopic transforaminal lumbar interbody fusion with arthroscopy. Clin Orthop Surg. 2018;10(2):248-252.

77. Zhou Y, Zhang C, Wang J, et al. Endoscopic transforaminal lumbar decompression, interbody fusion and pedicle screw fixation-a report of 42 cases. Chin J Traumatol. 2008;11(4):225-231.

Disclosures and COl: No direct or indirect conflicts of interest. The views expressed in this editorial represent those of the authors and no other entity or organization. The authors are accountable for all aspects of the work in ensuring that questions related to the accuracy or integrity of any part of the work are appropriately investigated and resolved. This manuscript is not meant for or intended to endorse any products or push any other agenda other than the associated clinical outcomes with endoscopic spine surgery. The motive for compiling this clinically relevant information is by no means created and/or correlated to directly enrich anyone due to its publication. This publication was intended to substantiate contemporary endoscopic spinal surgery concepts to facilitate technology advancements.

Corresponding Author: Kai-Uwe Lewandrowski, MD, Staff Orthopaedic Spine Surgeon, Center for Advanced Spine Care of Southern Arizona and Surgical Institute of Tucson, 4787 E. Camp Lowell Drive, Tucson, AZ 85712. Phone (520) 204-1495; Email: business@tucsonspine.com

Published 9 December 2020

This manuscript is generously published free of charge by ISASS, the International Society for the Advancement of Spine Surgery. Copyright (c) 2020 ISASS. To see more or order reprints or permissions, see http://ijssurgery.com. 